\title{
INCREASED HAEMATURIA IN NEPHRITIS DURING CORTISONE AND A.C.T.H. ADMINISTRATION \\ BY
}

\author{
L. MICHAELS and G. WALTERS \\ From the Department of Pathology, Bristol Royal Infirmary
}

(RECEIVED FOR PUBLCATION MARCH 9, 1953)

In the past few years cortisone and A.C.T.H. have been used in the treatment of nephritis. In the nephrotic state these drugs frequently produce a diuresis (Farnsworth, 1950a; Luetscher, Deming and Johnson, 1951). In haemorrhagic nephritis, however, the results have been variable (Thorn, Merrill, Smith, Roche and Frawley, 1950; Heller, Jacobson and Hammarsten, 1951).

The present paper reports an increase in the urinary red cell excretion which was observed in two cases of haemorrhagic nephritis which were treated with cortisone and A.C.T.H., and in one case, of doubtful diagnosis but thought to be haemorrhagic nephritis, treated with A.C.T.H.

\section{Method}

The method of measuring the haematuria was a modification of that described by Addis (1925). No special preparation of the patient, such as restriction of fluids, was carried out. Counts were made on the first morning specimens of urine. The patient was instructed to empty the bladder completely before going to sleep. The first morning specimen was collected, the volume and time over which the urine was secreted were noted, and, after thorough mixing, $30 \mathrm{ml}$. of urine was added to $0.25 \mathrm{~g}$. of the preservative mixture recommended by the Metropolitan Life Insurance Company (Gradwohl, 1943). The red cells in 1 c.mm. of concentrated or unconcentrated urine were counted in a FuchsRosenthal chamber. When the urine contained less than 100 red cells per c.mm. it was concentrated by centrifugation. The number of red cells excreted per hour was calculated.

\section{Case Reports}

Case 1.-A girl aged 13 was admitted to hospital in April, 1950, with gross haematuria and some oedema. She had been admitted to another hospital 18 months previously with the same symptoms, which had persisted ever since. On admission she was oedematous, and the urine contained numerous red cells, some granular casts and protein. The blood pressure was $140 / 90 \mathrm{~mm}$. $\mathrm{Hg}$ and the fundi were normal.

In spite of a period of rest in bed, the patient deteriorated and developed gross oedema, ascites and bilateral pleural effusions. In addition, the blood pressure rose to over $200 / 130 \mathrm{~mm}$. $\mathrm{Hg}$ and retinal haemorrhages and exudates with papilloedema developed. A.C.T.H., prepared by Dr. Max Reiss and kindly supplied by him, was then given for four days with little effect save that the patient stated that she could see better. A few days later, however, the publication containing Farnsworth's (1950b) first results in nephrotic patients arrived and it was seen that longer periods of therapy would be necessary. The patient had meanwhile begun to have fits which appeared to be controlled by intramuscular injections of magnesium sulphate. A.C.T.H. (Reiss) in a dose equivalent

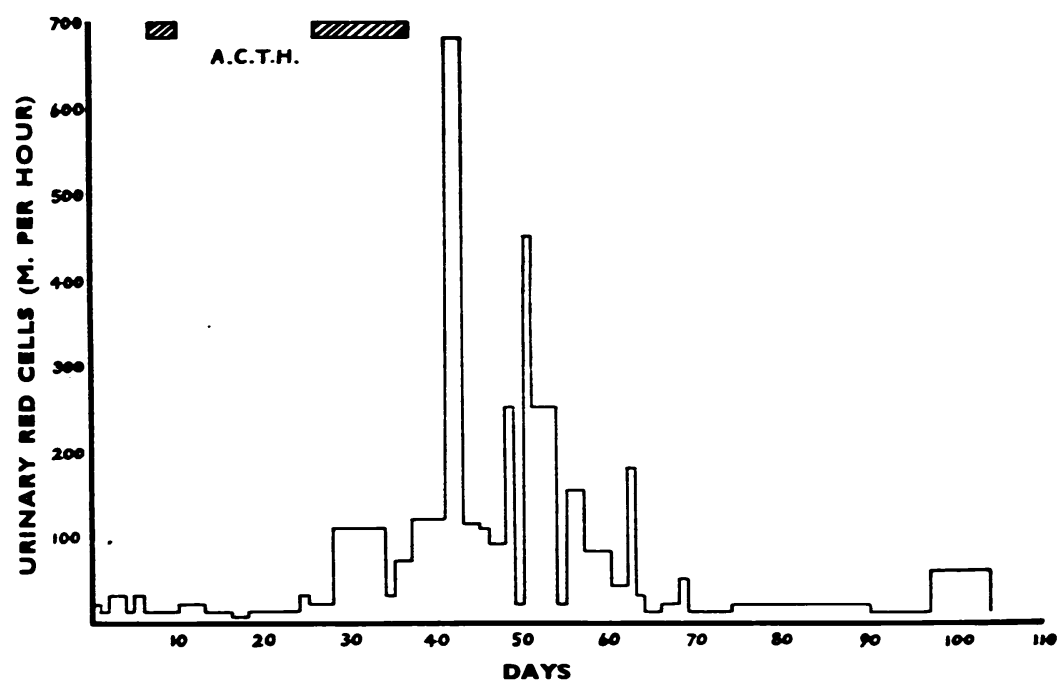

Fig. 1.-A.C.T.H. was administered on Days 7 to 10 inclusive and 26 to 37 inclusive. 
to $25 \mathrm{mg}$. (Armour) six-hourly was given for 10 days. After a few days the haematuria increased and the blood pressure rose to $260 / 160 \mathrm{~mm}$. Hg. However, the patient felt better, her sight seemed to improve and the papilloedema to diminish. Two to three days after this course of A.C.T.H. there was a short rise in the haematuria to 680 million red cells per hour (during the control period the level had been about 5 million) but nevertheless a considerable sustained diuresis occurred, the patient passing off all the oedema, ascites and pleural effusions, and losing $36 \mathrm{lb}$. in weight in the course of 29 days. After a period of about five weeks the amount of urinary red blood cells had gradually reverted to the control levels (Fig. 1.)

In 1951 she was re-admitted to hospital because of an increase in haematuria following a sore throat. On admission the blood pressure was $140 / 100 \mathrm{~mm}$. $\mathrm{Hg}$, and the fundi showed evidence of secondary optic atrophy. The urine contained very many red cells and occasional granular casts. A throat swab grew $\beta$-haemolytic streptococci of Lancefield's group A, but after seven days' treatment with intramuscular penicillin further swabs remained repeatedly negative.

After a control period of 16 days cortisone was given intramuscularly in doses of $50 \mathrm{mg}$. three times a day. There was an immediate increase in the haematuria from approximately 100 million red cells per hour to 220 million red cells per hour. Cortisone was stopped on the seventh day and the haematuria fell to previous levels. After an interval of 12 days a further course lasting three weeks was given, and again there was an immediate sharp increase of haematuria but this soon fell to pre-treatment levels and ultimately below (Fig. 2).

Case 2-A boy aged 9 years was first admitted to hospital in 1949 with the sudden onset of generalized cedema, proteinuria and numerous red cells and casts in the urine. After two months in hospital the oedema subsided, but proteinuria and haematuria were still present when he was discharged and persisted afterwards, so in April, 1951, he was re-admitted for a course of cortisone. On admission he looked well and there was no oedema. The blood pressure was $120 / 80 \mathrm{~mm}$. Hg.

After a control period of 14 days he was given cortisone, $50 \mathrm{mg}$. three times a day by intramuscular injection, for five days. On the second day of treatment the haematuria increased from 800,000 red cells per hour to $2,000,000$ red cells per hour and continued to rise.

At the same time the temperature rose to $101 \cdot 4^{\circ} \mathrm{F}$. and then continued at 99 to $100^{\circ} \mathrm{F}$. until the fourth day of treatment. The throat was injected and culture revealed a profuse growth of group $\mathbf{A} \boldsymbol{\beta}$-haemolytic streptococci. In view of the possible harmful effect of cortisone in an infection it was stopped after five days. The haematuria rapidly fell to pre-treatment levels. Cortisone was withheld until the haematuria had become constant-a period of about two weeks. It was then again administered and once more there was an increase in haematuria, though not to such a degree as occurred in the first instance. The temperature rose to $100 \cdot 4^{\circ} \mathrm{F}$. on the third day and returned to normal on the fifth day. Cortisone was stopped on the sixth day. The throat culture was still positive for $\beta$-haemolytic streptococi. A further course of cortisone was given after 13 days when the haematuria had again settled to a constant level. Once again there was an increase of haematuria, but throat cultures had now become negative so cortisone was continued for 26 days. The haematuria rose once more this time to about 5 million red cells per hour and then gradually decreased throughout the rest of the cortisone course. The final level

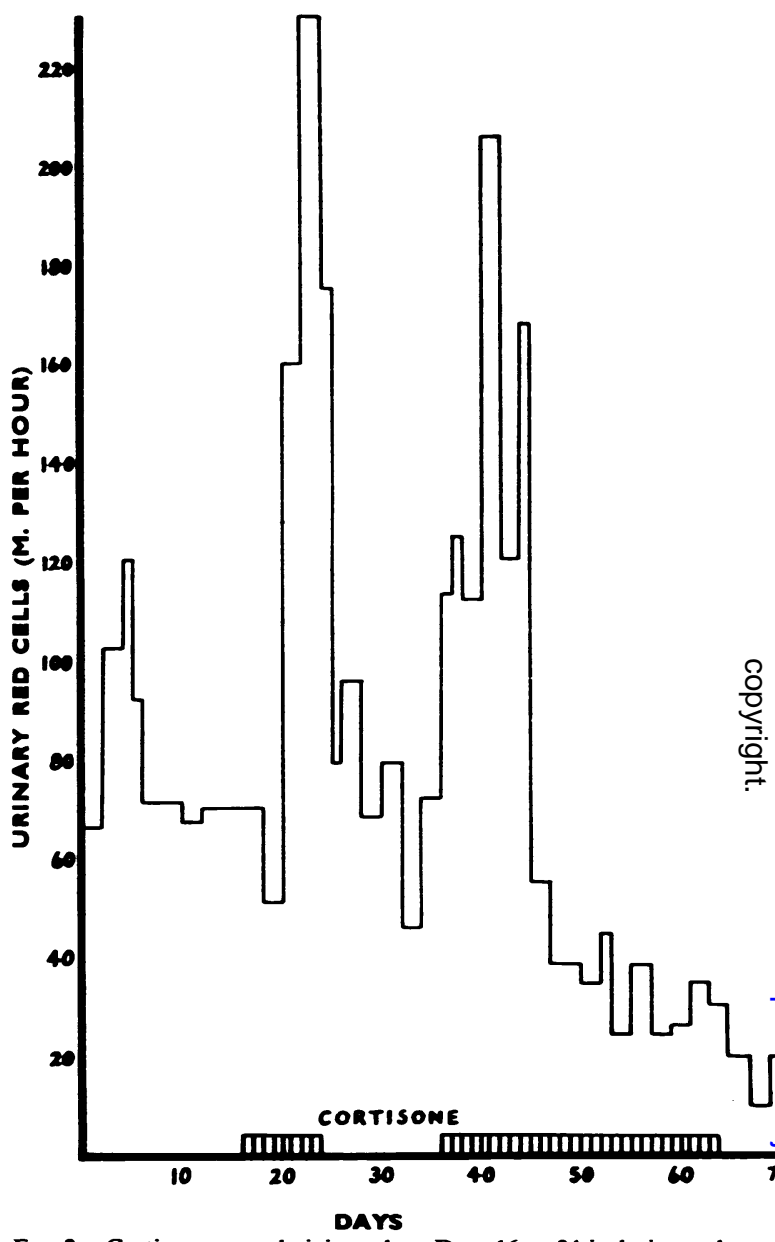

Fig. 2-Cortisone was administered on Days 16 to 24 inclusive and 36 to 64 inclusive.

of 100,000 to 200,000 red cells per hour was lower than the initial level of 650,000 to 900,000 red cells per hour (Fig. 3).

Case 3.-A man aged 21 was seen in 1951 with a suspected salivary calculus which, however, was not confirmed radiologically. He stated that he had been rejected from the Armed Forces in $\mathbf{1 9 5 0}$ for albuminuria. He had never had symptoms relating to the urinary system, but the urine was found to contain a large amount of protein, so he was admitted to hospital for investigation. He had no clinical oedema or any other abnormal physical signs. The blood pressure ranged from $140 / 90$ to $170 / 90 \mathrm{~mm}$. 
Hg. The urinary deposit contained red cells, white cells and cellular casts. There was a little impairment in the urine concentration and an intravenous pyelogram showed good concentration. Investigation for renal tuberculosis, including microscopy and culture of urine from the bladder and ureters, proved negative. The blood

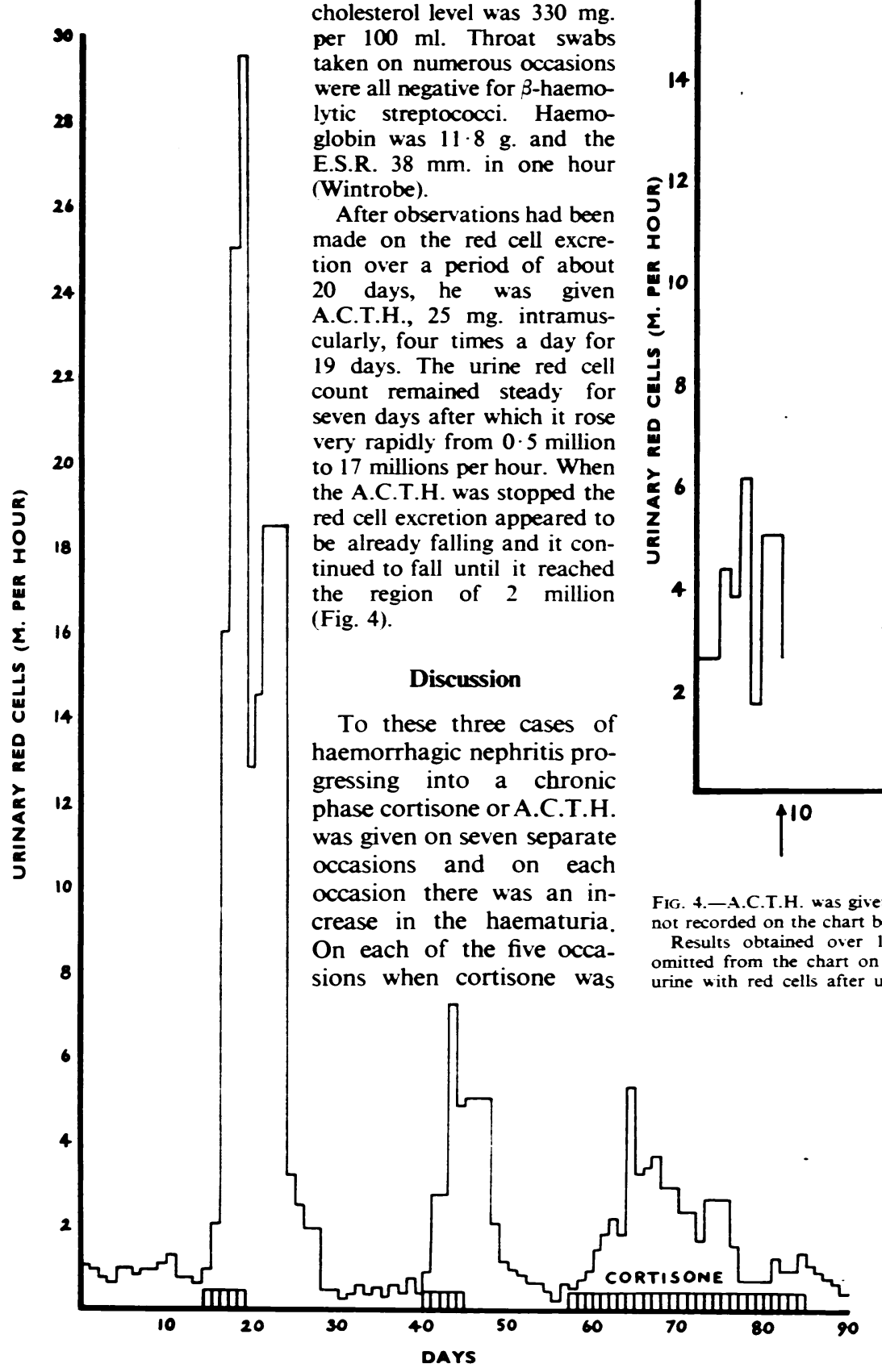

FIG. 3.-Cortisone was administered on Days 14 to 19 inclusive, 40 to 45 inclusive and 57 to 85 inclusive.

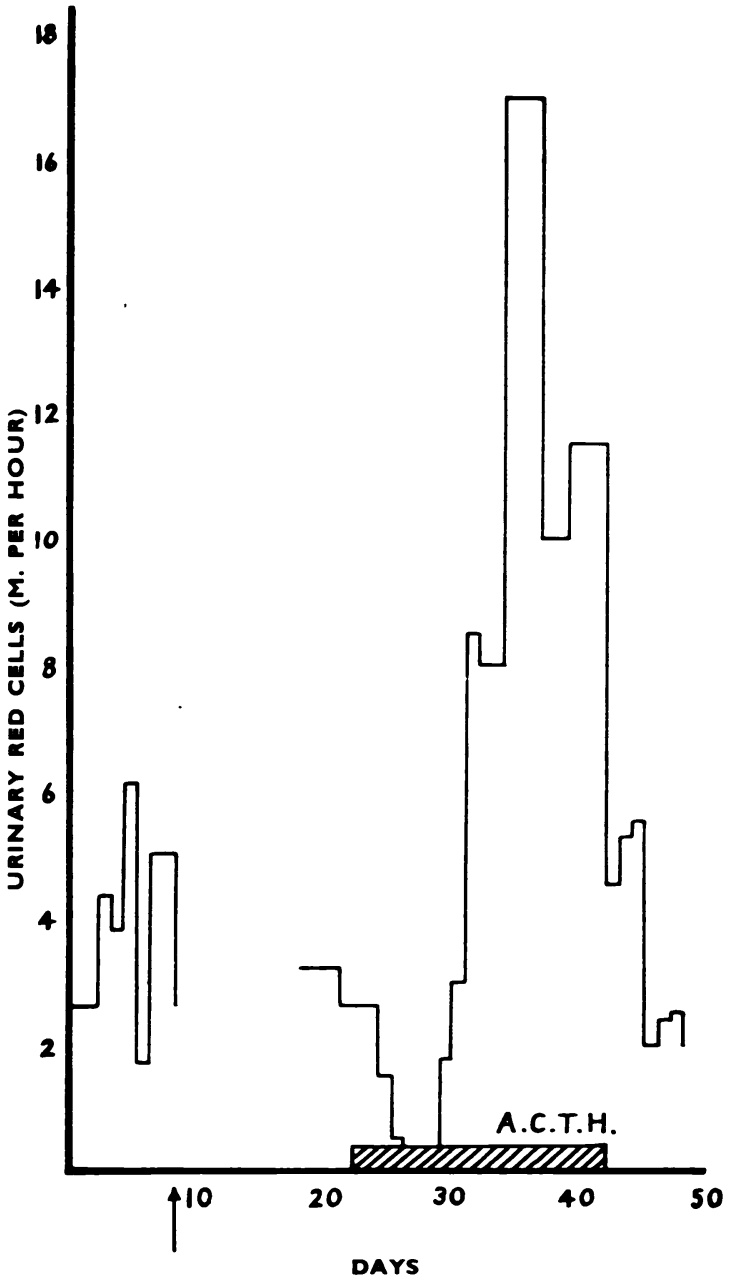

FIG. 4.-A.C.T.H. was given on Days 22 to 42 inclusive. Results are not recorded on the chart between Days 9 and 18 inclusive.

Results obtained over 10 days during the control period are omitted from the chart on account of heav contamination of the omitted from the chart on account of heavy contan

used the haematuria increased in from one to three days from the beginning of treatment. When A.C.T.H. was used the haematuria increased after eight days in Case 3 and immediately after beginning treatment in Case 1, though in the latter a much greater increase took place on the twelfth day after treatment had been stopped.

In Case 2 the first course of 
cortisone coincided with a streptococcal infection of the throat; in the second course, although scanty streptococci could still be grown, no increase in the number of colonies isolated took place nor was there any change in the appearance of the throat; in the third course of cortisone the haematuria increased although this time throat cultures were negative. It thus seemed more likely that the second and third exacerbations were due to a direct effect of cortisone on the kidney, rather than an indirect effect by stimulation of streptococcal inflammation in the throat. In the other cases the exacerbations all seemed to be related directly to cortisone or A.C.T.H.

The mechanism of this increased passage of red cells through the kidney during treatment of haemorrhagic nephritis with A.C.T.H. or cortisone is unknown.

\section{Summary}

Three courses of A.C.T.H. or cortisone were given in two cases of haemorrhagic nephritis, and one course of A.C.T.H. was given in a case of doubtful diagnosis but thought to be haemorrhagic nephritis.

In each patient there was a marked increase of haematuria, as measured by the urinary red cell count, every time the hormone was given. This increase took place in from one to eight days after treatment was begun.

We are grateful to Dr. G. A. Smart for suggesting this investigation and also for allowing us to publish reports on Cases 1 and 2 which were under his care. We are also glad to acknowledge Dr. J. E. Cates for his encouragement, advice and permission to publish Case 3.

\section{REFERENCES}

Addis, T. (1925). J. Amer. med. Ass., 85, 163.

Farnsworth, E. B. (1950a). Proc. Soc. exp. Biol., 74, 60. - (19506). In Proceedings of the First Clinical A.C.T.H. Conference, Chicago, ed. Mote, J. R., pp. 297-317. London.

Chicago, ed. Mote, J. R., pp. 297-317. London.
Gradwohl. R. B. H. (1943). Clinical Laboratory Methods and Diagnosis, 3rd ed., vol. 1, p. 42. London.

Heller, B. I., Jacobson, W. E. and Hammarsten, J. F. (1951). J. Lab. clin. Med., 37, 133.

Luetscher, J. A. Deming Q. B. and Johnson, B. B. (1951). J. clin. Invest., 30, 1530.

Thorn, G. W., Merrill, J. P., Smith, S., Roche, M. and Frawley, T. F. (1950). Arch. intern. Med., 86, 319. 